\title{
HOMOPARENTALIDADE: UMA ENTRE OUTRAS FORMAS DE SER FAMÍLIA
}

\author{
Maria Consuêlo Passos*
}

\section{RESUMO}

A família impõe hoje, àqueles que se dedicam a estudá-la, um grande desafio. Suas transformações são cada vez mais visíveis, tanto do ponto de vista das relaçôes intragrupo como daquelas mantidas com outras instituiçôes sociais. Neste trabalho, procuramos examinar a homoparentalidade, acreditando que essa modalidade de família apresenta as mais significativas mudanças nas relações conjugais e parentais, uma vez que nega o paradigma do qual se origina a família: a diferenciação sexual. O desejo do casal de ter um filho, o luto pela impossibilidade biológica de concebê-lo, a escolha de uma forma, dentre várias, para realizar esse desejo, a relação com um terceiro sujeito que viabiliza a vinda do filho são algumas das questóes que enfrentaremos aqui.

Palavras-chave: família, criança, casal, homoparentalidade

\section{Abstract}

HOMOPARENTALLY: ONE AMONG OTHER WAYS OF BEING A FAMILY

Nowadays the family imposes a great challenge to those who dedicate themselves to study it. Its transformations are getting more and more visible, both from the point of view of the relationships internal to the family and of the relations kept with the other social institutions. In this work, we try to examine the homo-parentally, believing that this modality of family presents the most significant changes in the conjugal and parental relations, since it denies the paradigm from which the family originates: the sexual differentiation. The will of a couple to have a son, the mourning for the biological impossibility to conceive it, the choice of a way, amongst several, to carry through this desire, the relation with a third person that makes possible the coming of the son, are some of the questions we will face here.

Keywords: family, children, couple, homoparentally

\footnotetext{
* Professora da PUC-SP e da Universidade de São Marcos.
} 


\section{REFLEXÕES INICIAIS}

As diferentes modalidades de família surgidas nos últimos tempos expressam transformações muito significativas na relação família-indivíduo-sociedade. Algumas dessas modalidades estão fundadas em nuances muito singulares; no entanto, nenhuma é tão revolucionária quanto a família homoparental, já que esta destitui um princípio fundamental na constituição do grupo familiar: a diferenciação sexual. Embora a homossexualidade tenha uma longa história em vários cenários culturais, nos quais, muitas vezes, as pessoas tinham filhos, só muito recentemente a homoparentalidade vem se tornando mais visível no contexto social brasileiro.

Mesmo assim, ainda hoje só podemos acessá-la como objeto de pesquisa, por meio de informaçôes de amigos ou figuras que circulam na mídia como ícones de uma pretensa vanguarda social. Fora desses contextos, sobrevivem, ainda, a dissimulação e o medo de declarar, ou mesmo o "nada a declarar", o que atesta sua clandestinidade. As instituições, evidentemente, corroboram essa situação. Há pouco ouvi o depoimento de uma moça que dizia: "Ainda bem que o juiz não descobriu minha orientação sexual, pois, se o fizesse, certamente não teria autorizado a adoção do meu filho". Muitos subterfúgios criados pelos homossexuais para assegurar e/ou legitimar o direito de ter filhos, ou de constituir família, acabam por engendrar padrôes relacionais muito diferentes daqueles hegemônicos na família dita tradicional, constituída pelos padrōes patriarcais. Neste sentido, a pergunta que se impõe é: estariam estes padrões a serviço de uma desordem nos laços que instituem o grupo familiar, ou seriam eles constitutivos de uma nova ordem relacional no interior deste grupo? Eis a questão que debateremos a seguir.

\section{PoR UMA NOVA ÉTICA RELACIONAL}

A multiplicidade de formas revelada pela família hoje exige uma boa dose de flexibilidade de quem sobre ela se debruça de modo a assegurar que posiçóes préconcebidas ou preconceituosas não prejudiquem a compreensão dos distintos laços que estruturam as famílias. De um modo geral, buscamos um entendimento das diferentes modalidades de família a partir das premissas históricas do patriarcado. A homoparentalidade não foge a esta regra e, nesse sentido, se torna difícil, $\mathrm{e}$ às vezes perigoso, o debate que se estabelece em relação a suas especificidades e seu potencial de subjetivação, uma vez que é muito comum sua condenação $a$ priori, por não oferecer um quadro referencial compatível com aquele instituído pelo status quo patriarcal. Penso que aí está um grande equívoco, já que, nesse 
caso, é impossível um ajuste entre modelos; afinal, as relações homoparentais exigem uma configuração de funções e lugares distinta da parentalidade heterossexual.

Embora não possamos falar em uma total falência do sistema patriarcal, é preciso reconhecer que suas leis e noções internas não dão mais conta das demandas relacionais criadas nas sociedades liberais e democráticas, onde os cidadãos criam e recriam mais livremente suas experiências afetivas. Além disso, contam com recursos técnicos da medicina reprodutiva para escolher como desejam conceber seus filhos. Neste sentido, o declínio do patriarcado tem se mostrado evidente em muitos contextos relacionais, dos quais a família é o mais visível, mas ele permanece ainda com certa força no imaginário social de sociedades ainda frágeis do ponto de vista do favorecimento da expressão livre de seus cidadãos. Isto se verifica não só nas manifestações afetivas, mas na forma como é conduzida, com freqüência, a política das relações entre gêneros. Vivemos, assim, muitas contradições: na prática acompanhamos a diversificação dos modelos familiares, mas em tese continuamos, em grande medida, a considerá-los a partir de concepçôes que se tornam cada vez mais obsoletas.

Ao refletir sobre tais ambigüidades, Parseval defende a idéia de que existe uma ética geral da procriação. Ela afirma que:

A ética que rege as famílias homoparentais, como a da adoção ou a que deveria reger as procriações medicamente assistidas, só pode ser compreendida em um quadro de uma ética mais global, fundada sobre a justiça inerente às transformações humanas. O equilíbrio relacional entre os diferentes protagonistas destas histórias tem este preço. É neste sentido que o "fio vermelho" da ética relacional me parece a mais heurística a considerar, centrada sobre a responsabilidade em relação às gerações futuras (Parseval, 1998: 09).

A partir desta posição, inferimos três aspectos que julgamos fundamentais para a compreensão das novas configurações familiares: sua consideração dentro de um contexto mais amplo das relaçóes sociopolíticas de uma dada realidade; a observação de uma ética relacional que dê conta das transformações que ocorrem nos pequenos grupos regidos pelas redes de afeto; e, por fim, o entendimento de que uma ética relacional que assegure as especificidades de cada contexto possa evitar, em futuras gerações, o martírio advindo de posições preconceituosas que excluem os sujeitos por não pertencerem aos padrões estabelecidos e não se regularem pelos valores hegemônicos.

Estamos, com isso, propondo que as novas formas de ser família hoje sejam consideradas a partir de uma ética que leve em conta as demandas afetivas dos 
sujeitos nelas envolvidos. Esta ética deve estar assentada, portanto, nas diferentes formas de conjugalidade, parentalidade e filiação que configuram um contexto familiar baseado nos laços de afeto. Seus princípios adviriam não mais das leis gerais que fundamentam a ordem familiar patriarcal, mas das novas redes que sustentam as relações de afeto nas novas famílias. Isto significa dizer que ela está sendo reconstruída permanentemente a partir das expressões relacionais que se diferenciam, repercutindo no contexto da sociedade mais ampla, ao mesmo tempo que são marcadas pelas tramas sociais.

Vejamos a seguir algumas especificidades da família homoparental.

\section{A CONSTITUIÇÃO DOS LAÇOS HOMOPARENTAIS}

Os casais homossexuais que desejam ter filhos enfrentam o desafio de encontrar uma forma menos dolorosa para a realização dos seus desejos. Isto porque a impossibilidade de gerar filhos exige um trabalho psíquico que envolve, em princípio, duas questões centrais. A primeira se refere às contradições vividas por cada membro do casal que, se, por um lado, deseja ter filhos, por outro se sente impedido de gerá-los. A decisão parece impor um trabalho de difícil elaboração, uma vez que se trata de abrir mão de um princípio narcísico de continuidade biológica e aceitar a submissão a agentes externos no que diz respeito à concepção do filho. A segunda diz respeito ao esforço empreendido pelo casal no sentido de encontrar a forma menos ameaçadora de conceber esse filho. Digo ameaçadora porque, seja qual for a modalidade escolhida, haverá sempre uma incompletude e uma impossibilidade de gerar, marcadas no desejo projetado no filho.

De acordo com Parseval, esse tem sido um grande dilema na assunção da maternidade/paternidade pelos homossexuais; para ela:

O trabalho do luto da fertilidade está no centro das questôes de esterilidade. Não poder transmitir a vida é uma ferida existencial muito pesada; ferida que necessita de um longo tempo e um longo trabalho de luto, etapa essencial em todas as histórias de esterilidade do casal (os casais homossexuais em primeiro lugar). Sabe-se que os lutos não feitos podem dificultar, travar o processo de tornar-se pai/mãe. Vemos em diferentes tratamentos como os impasses administrativos, longe de ajudar os casais a fazerem o luto de sua fertilidade, ampliam, ao contrário, suas dificuldades (Parseval, 1998: 17).

Sabe-se que hoje os homossexuais têm diferentes possibilidades de ter seus filhos. Todas, entretanto, exigem do casal um esforço e um trabalho elaborativo 
para definir e assumir as contingências da gestação e do parto, às vezes de difícil assimilação. Podemos pensar, nas seguintes composições familiares:

1. A recomposição, na qual um membro do casal traz para sua relação homossexual o(s) filho(s) de um casamento heterossexual anterior.

2. A co-parentalidade, em que um dos membros do casal homossexual gera um filho com um homem ou uma mulher, não necessariamente homossexual, e este filho passa a fazer parte do núcleo parental de um dos pais biológicos.

3. Uma terceira forma é a adoção, legalizada ou não, feita pelo casal.

4. Há ainda a possibilidade da inseminação artificial realizada com o sêmen de um doador, no caso de um casal de mulheres, ou de uma mãe substituta, que gera um filho com o sêmen de um dos parceiros do casal homossexual masculino.

Em todas elas há um terceiro, mediando o desejo de conceber um filho. Em última análise, o casal depende de um outro para realizar seu projeto. Esse outro que permanecerá no imaginário da família, com o qual os pais precisam conviver, se interpóe na formação dos laços afetivos com os filhos de modos diferentes, dependendo de como ele é assimilado/elaborado por esses pais. Algumas vezes, o outro imaginário toma a forma de uma figura que se superpóe aos pais. Outras vezes, aparece como sombra enigmática que acompanha e perturba o reconhecimento dos filhos, podendo ainda ser assimilado como elemento sem o qual a filiação não existiria.

Assumir essa falta, por meio de um trabalho de luto, é fundamental, pois permite ao casal instaurar a parentalidade em bases mais sólidas, já que exigiu um trabalho de elaboração das suas impossibilidades de gerar filhos juntos. Todas essas negociações têm uma profunda repercussão quando se trata de pensar os laços constitutivos das famílias homoparentais, sobretudo no momento de sua instauração.

Quando se trata do processo de filiação, em qualquer tipo de família, é preciso ressaltar, em um primeiro plano, as funçôes que o casal e cada um dos membros, individualmente, exercerá junto à criança, inscrevendo-a e a eles próprios em uma cadeia simbólica. Os primórdios dessa função surgem quando o filho é apenas um desejo e prossegue quando a criança nasce. Há um processamento psíquico dos laços produzidos a partir de investimentos constituídos pelas representações e afetos que circulam reciprocamente entre os membros da inter-relação.

Embora tratada aqui de forma supersimplificada, essa conceituação serve de parâmetro para pensar os fundamentos mais universais das funções familiares, que dizem respeito à recepção, ao acolhimento, ao reconhecimento e à inserção da criança em uma cadeia de transmissão psíquica. Essas funções, engendradas no 
contexto das novas concepções de família, possibilitam um espaço no qual se torna plausível a não-diferenciação sexual no triângulo familiar.

As referências para pensar essa triangulação não podem ser jamais aquelas fundadas na hegemonia do poder paterno, nem tampouco no princípio de gênero e de diferenciação sexual. Tratando dessa nova família, Roudinesco afirma:

De agora em diante esta não será mais vista apenas como uma estrutura do parentesco que restaura a autoridade derrotada do pai, ou sintetizando a passagem da natureza à cultura através dos interditos e das funçóes simbólicas, mas como um lugar de poder descentralizado e de múltiplas aparências. Em lugar da definição de uma essência espiritual, biológica ou antropológica da família, fundada no gênero e no sexo ou nas leis do parentesco, e em lugar daquela, existencial, induzida pelo mito edipiano, foi instituída outra, horizontal e múltipla, inventada pelo individualismo moderno e logo dissecada pelo discurso dos especialistas. Essa família se assemelha a uma tribo insólita, a uma rede assexuada, fraterna, sem hierarquia nem autoridade, na qual cada um se sente autônomo ou funcionalizado (Roudinesco, 2003: 155).

Esta posição da autora segue a mesma direção das idéias que procuramos sugerir ao longo destas reflexôes, ou seja, a perspectiva de que não podemos nostalgicamente nos reportamos ao modelo clássico de família, usando-o como única referência dos modelos atuais, sem corrermos o risco de caricaturarmos as experiências afetivas que são criadas nos novos contextos. Neste sentido, a família de hoje impõe, no lugar da hegemonia dos papéis e dos lugares fixos, uma maior flexibilidade na constituição de posições e funções dos membros do grupo. Assim, ganha muito mais força a forma como os pais do mesmo sexo, cada um a sua maneira, representa este filho como um outro que atualiza seu desejo de transmissão e continuidade, investindo-o, portanto, de um afeto fortemente narcísico.

Nesse caso, pouco importa se a triangulação é constituída por dois homens e um filho ou por duas mulheres e uma filha, a circulação dos afetos se faz numa circunstância em que a identificação entre os pais e os filhos não exige mais os contornos de antes. Em outras palavras, o jogo especular da triangulação edipiana, no qual a identificação com o igual exigia a presença do diferente, perde a sua força. Parece ganhar mais relevância no jogo entre iguais o processamento psíquico dos desejos dos pais, associado ao reordenamento que a criança faz do material percebido. Nesse caso, o filho adquire cada vez mais um estatuto de ordenador de sua herança, herança esta engendrada em um ambiente que o reconhece como autor de sua própria história. 
Em um contexto onde as referências da família patriarcal caem em desuso, releva-se o princípio do reconhecimento, não como compensação pelo enfraquecimento das identificações no modelo edipiano clássico, mas como princípio fundamental do processo de filiação. Para Kaës, a filiação é o reconhecimento que os pais fazem, ao mesmo tempo, do lugar que a criança ocupa em suas continuidades narcísicas, da precedência dos seus desejos na criação do filho e de sua alocação na ordem das geraçôes. Segundo o autor:

Este reconhecimento é também uma precedência necessária à inscrição do estatuto civil da criança, sobre o registro ou sobre a árvore dos ancestrais: signos de re-conhecimento prévio para o seu surgimento como sujeito do desejo, sujeito da palavra e sujeito do grupo. É neste triplo assujeitamento que cada um e cada uma é declarado(a), conhecido(a) e reconhecido(a) filho ou filha de (Kaës, 2000: 64).

Evidentemente, estas condições existem em qualquer relação parental, mas, quando se trata de um grupo familiar formado por pais do mesmo sexo, é preciso considerar uma negociação em torno da funcionalidade do grupo como tal, das suas posiçōes internas, o que parece supor, como foi dito anteriormente, que nesta funcionalidade ganhe sentido o fantasma do outro, responsável pela concepção biológica do filho. Nessa equação, é preciso ressaltar que este outro passa a ter uma função simbólica que não poderá mais ficar ausente do processo de subjetivação da criança.

O papel desse outro deixa de ser apenas instrumental para ocupar um estatuto simbólico, uma vez que ele faz parte da rede de desejos dos pais como elemento que medeia e viabiliza a concepção da criança e lhes permite experienciar a castração. A atribuição de sentidos a este agente permitirá aos pais construírem seus lugares e funções perante o filho sem que haja ameaças ou persecutoriedades. Só assim será possível pensar a diferenciação e os limites entre a reprodução biológica e a reprodução social da humanidade, o que parece corroborar uma nova ordem simbólica na família.

Ainda assim, cabe questionar: quais as posiçōes que estariam sustentando a composição interna desta nova ordem familiar? Ao menos no que concerne à homoparentalidade, alguns matizes são fundamentais:

1. Ausência de papéis fixos entre os membros. Isso significa que a estrutura do grupo familiar deve suportar trocas e deslocamentos de papéis e lugares.

2. Prevalência de uma horizontalidade nas relações internas, marcada pela inexistência de hierarquias e por uma circulação permanente das lideranças no grupo. 
3. Múltiplas formas de composição familiar e, conseqüentemente, de formação dos laços afetivos e sociais, o que possibilita distintas referências de autoridade, tanto dentro do grupo como no mundo externo.

4. Tendência a uma constituição de sujeitos que se filiam não só à família, mas também a grupos onde preponderam os laços de amizade.

Estas características, que reformulam a funcionalidade do grupo, não implicam, necessariamente, uma minimização das referências de autoridade no processo de desenvolvimento da criança. Elas serão sempre e inevitavelmente necessárias. Trata-se, isso sim, de considerar que os deslocamentos processados nas relaçóes internas da família impõem, além de uma nova concepção de autoridade, o reconhecimento de que ela tem sido exercida "silenciosamente" por outras figuras próximas à criança. É o caso, por exemplo, da autoridade exercida pelos irmãos. Sobre esta questão, Costa (2000) afirma que a autoridade da função paterna só tinha um poder hegemônico porque o pai visível sustentava uma realidade, simbólica, real e imaginária, insuspeitável. Para o autor, aquele pai não mais existe e em seu lugar ganham força outros pares, como os irmãos. Aliás, os irmãos sempre tiveram a função de sustentar a força do pai, à custa de algumas renúncias - não foi isso que Freud nos ensinou? Pois bem, ao deslocamento do pai sucede o deslocamento de outros pares, sobretudo dos irmãos, que, aliás, têm lugar destacado na estruturação psíquica da família. Mas este é outro debate.

\section{IMPASSES NA CONSOLIDAÇÃO DE UMA NOVA ORDEM FAMILIAR}

Ressaltei anteriormente a impossibilidade de seguirmos adotando as mesmas referências das famílias patriarcais nas distintas configurações que surgem na sociedade atual. Gostaria de evidenciar agora alguns significados da manutenção de uma ordem obsoleta na formação dos novos grupos familiares e, em certa medida, no processo de subjetivação dos filhos. É preciso assinalar, no entanto, que, mesmo em declínio, algumas leis do sistema patriarcal brasileiro ainda têm grande repercussão em nossa sociedade, em particular nos pequenos grupos sociais. A idéia do homem provedor e da mulher responsável pela educação dos filhos, por exemplo, ainda se mantém em grande medida no Brasil.

Embora nossas pesquisas ainda não nos permitam trazer dados consistentes sobre os filhos das famílias homoparentais, algumas reflexões nos permitem, ao menos, acenar com certas perspectivas que repercutem na dinâmica destas famílias e, conseqüentemente, na constituição psíquica de seus filhos.

Disse acima que o reconhecimento do filho decorre, entre outros aspectos, da forma como ele foi imaginariamente concebido pelos pais. Pois bem, e se ele 
foi concebido sob o manto da vergonha, de um desejo que se quer calar? Não seria essa uma marca que o estrutura? Uma espécie de falta que antecipa a própria castração como fundamento da psique? Por outro lado, como podemos pensar a chegada de uma criança envolta no silêncio ou na mentira como acontece muito freqüentemente? Enfim, todas estas questôes precisam ser enfrentadas, não para criar hostilidades ou patologizar as famílias homoparentais, mas para ressaltar possíveis intercorrências geradas pelas sociedades que, ainda hoje, estigmatizam e negam o que jamais poderá ser negado: a possibilidade que deve ter cada sujeito de criar e recriar livremente sua vida.

Muitas vezes, as estratégias utilizadas pelos homossexuais para assegurarem o direito de constituir família e ter filhos possibilitam a manutenção de padrões relacionais que, em vez de transgredir o que para eles é inaceitável - como preconceitos velados e até escancarados -, reproduzem o que há de mais conservador nessas famílias. É muito freqüente pais ou mães homossexuais silenciarem em relação à existência do(a) parceiro(a), pois como pais celibatários são muito mais aceitos socialmente. Tais estratégias revelam que a ausência de uma legitimidade jurídica e social dificulta a constituição dos laços homoparentais e, por vezes, gera artifícios dissonantes com a formação das referências demandadas pela criança, as que são estruturantes dos laços afetivos em qualquer tipo de família: cuidar, acolher, conter, reconhecer e inserir a criança em uma cadeia de transmissão geracional. A criança também precisa ser reconhecida por ela mesma e não como possibilidade de mitigar as faltas e frustrações dos seus pais. Ela precisa, sobretudo, ter acesso, em quaisquer circunstâncias, à história verdadeira de sua origem.

A clandestinidade na qual se mantém boa parte das famílias homoparentais sem dúvida gera sofrimento para seus membros e, nesse caso, as crianças são as maiores vítimas. De um modo geral, se atribui à não-diferenciação sexual os males dos quais as crianças serão vítimas, embora até hoje não haja estudos que atestem essa enunciação. No caso das novas formas de família, em particular na família homoparental, parece ter sido criado um ciclo vicioso onde fenômenos novos devem caber em teorias cujas referências empíricas estão em extinção.

É nesse sentido que proponho, na abordagem da homoparentalidade, uma concepção que procure discernir, em um primeiro plano, quais as demandas da criança em relação à família. Dito de outro modo, é preciso verificar quais as premissas relacionais dentro do espaço familiar que são fundamentais para a estruturação psíquica da criança. Assim, será possível compreendermos se as condições inerentes à estruturação do psiquismo infantil, ditas acima, estão ou não presentes na parentalidade homoafetiva. Nesse caso, mudamos de paradigma e evitamos o uso abusivo de predeterminações e preconceitos. 
Tudo isso nos leva a pensar que há uma indecifrável plasticidade no psiquismo humano, o que nos impõe uma maior prudência quando se trata de afirmações categóricas ou previsões quanto ao que será prejudicial ou favorável à sua constituição. Aqui há apenas uma certeza, a de que é imprescindível olharmos para essas famílias com flexibilidade e bom senso, procurando instaurar uma ética relacional que possibilite a expressão dos sujeitos em suas singularidades sócio-afetivas.

Para finalizar, gostaria de dizer que as condiçôes por meio das quais os homossexuais constroem seus laços afetivos, no Brasil, estão longe de obter uma legitimidade social e jurídica e, enquanto esse quadro não se reverte, teremos famílias, pais e filhos envergonhados. Resta explorarmos os sentimentos desta vergonha nas produções de subjetividade que decorrem daí. Cabe-nos também o enfrentamento rigoroso das teorias, que são insuficientes para dar conta das profundas transformações processadas nas famílias, sobretudo em seus enredamentos afetivos.

\section{REFERÊNCIAS BIBLIOGRÁFICAS}

Cadoret, A. (2002). Des parents comme les autres - Homosexualité et parenté. Paris: Odile Jacob.

Costa, J. F. (2000). Playdoier pelos irmãos. Em Kehl, M. R. (Org.). Função fraterna (pp. 7-30). Rio de Janeiro: Relume Dumará.

Dubreuil, É. (1998). Des parents de même sexe. Paris: Odile Jacob.

Gross, M. (Org.), (2000). Homoparentalités, état des lieux - Parents et différence des sexes. Issy-les-Moulineaux: ESF.

Kaës, R. (2000). Filiation et affiliation. Em Le divan familial (pp. 45-56). Paris: In Press. Nadaud, S. (2002). Homoparentalité. Une nouvelle chance pour la famille?. Paris: Arthème Fayard.

Parseval, G. (1998). Préface. Em Dubreuil, É. Des parents de même sexe (pp. 9-17). Paris: Odile Jacob.

Passos, M. C. (2005). Nem tudo que muda, muda tudo: um estudo sobre as funções da família. Em: Féres-Carneiro, T. (Org.). Família e casal - efeitos da contemporaneidade (pp. 11-23). Rio de Janeiro: PUC-Rio.

Roudinesco, E. (2003). A família em desordem. Rio de Janeiro: Zahar.

Recebido em 21 de junho de 2005 Aceito para publicação em 3 de outubro de 2005 